\title{
Silica sulfuric acid: a reusable solid catalyst for one pot synthesis of densely substituted pyrrole-fused isocoumarins under solvent-free conditions
}

\author{
Sudipta Pathak, Kamalesh Debnath and Animesh Pramanik ${ }^{*}$
}

Open Access

\author{
Full Research Paper \\ Address: \\ Department of Chemistry, University of Calcutta, 92, A. P. C. Road, \\ Kolkata-700 009, India; Fax: +91-33-2351-9755; Tel: \\ $+91-33-2484-1647$ \\ Email: \\ Animesh Pramanik* - animesh_in2001@yahoo.co.in \\ * Corresponding author \\ Keywords: \\ green chemistry; pyrrole-fused isocoumarin; reusable solid support; \\ silica sulfuric acid; solvent-free condition
}

Beilstein J. Org. Chem. 2013, 9, 2344-2353. doi:10.3762/bjoc. 9.269

Received: 01 August 2013

Accepted: 07 October 2013

Published: 04 November 2013

Associate Editor: J. P. Wolfe

(c) 2013 Pathak et al; licensee Beilstein-Institut. License and terms: see end of document.

\begin{abstract}
A convenient and efficient methodology for the synthesis of densely substituted pyrrole-fused isocoumarins, which employs solidsupported silica sulfuric acid (SSA) as catalyst, has been developed. When the mixture of ninhydrin adducts of acetylacetone/ethyl acetoacetate and primary amines was heated on the solid surface of SSA under solvent-free conditions, the pyrrole-fused isocoumarins were formed in good yields. This synthetic method has several advantages such as the employment of solvent-free reaction conditions without the use of any toxic reagents and metal catalysts, the ease of product isolation, the use of a recyclable catalyst, the low cost, the easy availability of the starting materials, and the excellent yields of products.
\end{abstract}

\section{Introduction}

Isocoumarins are an important class of naturally occurring lactones [1-3], which has attracted the attention of chemists because of their various biological activities such as antioxidative [4], anticancer [5] and antifungal activities [6]. The development of a new and efficient methodology for the synthesis of biologically potent isocoumarins and their carbo/hetero annulated analogues has drawn great attention of synthetic as well as medicinal chemists [7-9]. Various methodologies for the synthesis of isocoumarins have been reported such as the reaction of $o$-halobenzoic acids and 1,3-diketones through a coppercatalyzed tandem sequential cyclization/addition/deacylation process $[10,11]$, an iridium-catalyzed oxidative lactonization or an intramolecular cyclization reaction of $\delta$-ketoaldehydes [12], a ruthenium-catalyzed aerobic oxidative cyclization of aromatic acids with alkynes [13], an $\mathrm{FeCl}_{3}$-promoted regioselective annulation of $o$-(1-alkynyl)benzoates with disulfides [14], a Heck-Matsuda cyclization reaction [15], a 6-endo-dig cyclization of heteroaryl esters to alkynes [16], or a Pd(II)-mediated cyclization of $o$-allylbenzaldehydes [17]. Salvinorin A, a natural product isolated from the hallucinogenic sage Salvia divinorum, which also contains a saturated isocoumarin ring, has been synthesized [18]. Although these methods are useful for the 
synthesis of isocoumarin derivatives, the reactions involved in the synthesis still suffer from some serious limitations such as the use of expensive and hazardous reagents [12] and toxic metal catalysts $[10,11,15,17]$. Some of the reactions need laborious and time consuming procedures $[12,13,17]$, or drastic reaction conditions and with only low to moderate yields [16] On the other hand, although a number of synthetic methods have been developed for the construction of densely substituted pyrrole rings [19-21], not a single report has been given on the synthesis of pyrrole-fused isocoumarins with the help of green methodology, so far. Therefore, the development of an environmentally friendly and safer reaction methodology following the green chemistry principles is essential for the synthesis of pyrrole-fused isocoumarins.

The employment of a reusable solid supported/heterogeneous catalyst for the efficient synthesis of heterocyclic compounds remains a challenge to chemists in laboratories and in the industry $[22,23]$. Reactions with reagents that are immobilized on inorganic solid supports show several advantages over the conventional reactions in solution because of simple work-up procedures, improved product yields, greater ease of purification, shorter reaction times, milder reaction conditions, and recyclability of the catalyst [24]. In the recent years, silica sulfuric acid (SSA) has shown immense potentiality as an efficient and easily retrievable solid catalyst in various important organic syntheses under solvent-free conditions [25]. The high catalytic activity, the operational simplicity and the recyclability of SSA can be exploited in the industry for the synthesis of various drugs and pharmaceuticals. SSA, a product that is easily synthesized from silica gel and chlorosulfonic acid [26], was observed to improve the reactivity and selectivity in carbon-carbon bondformation reactions [27,28], in cycloaddition reactions [29,30], in protection-deprotection reactions of multistep syntheses [3133], in esterifications [34] and in syntheses of heterocycles [35]. Since we are actively involved in the synthesis of biologically important heterocycles [36-42], we wish to report herein a green methodology for the construction of pyrrole-fused isocoumarins, which uses SSA as a solid-supported acid catalyst under solvent-free conditions (Scheme 1, present work).

\section{Results and Discussion}

Recently, we have reported that the enamines $\mathbf{3}$ generated from acetylacetone (1) and amines 2 react with ninhydrin to form the cyclic hemiaminal dihydroxyindenopyrroles 4 . Subsequently intermediates $\mathbf{4}$ produce the pyrrole-fused isocoumarins $\mathbf{5}$ upon heating in glacial acetic acid with a catalytic amount of conc. $\mathrm{H}_{2} \mathrm{SO}_{4}$ (Scheme 1, previous work) [38]. It was observed that in the above synthesis the intermediate dihydroxyindenopyrroles 4 were needed to be isolated for further reaction to get the final products 5 in pure form. Otherwise some acetylated amines were always produced as byproducts. Besides, the formation of 4 from 3 did not proceed significantly when the enamines of ethyl acetoacetate were employed, because under acidic conditions, the enamines of ethyl acetoacetate readily hydrolyze and the free amines react with ninhydrin to form Schiff bases. To overcome the above problems we have designed an operationally simple one-pot reaction for the synthesis of pyrrolefused isocoumarins (5 or 8 ) from the ninhydrin adducts of acetylacetone/ethyl acetoacetate (6 or 7) [43] and primary amines 2 under solvent-free conditions (Scheme 1, present work).

In order to explore the role of the different catalysts and solvents in the preparation of pyrrole-fused isocoumarins, an optimisation study was carried out with the model reaction

previous work:

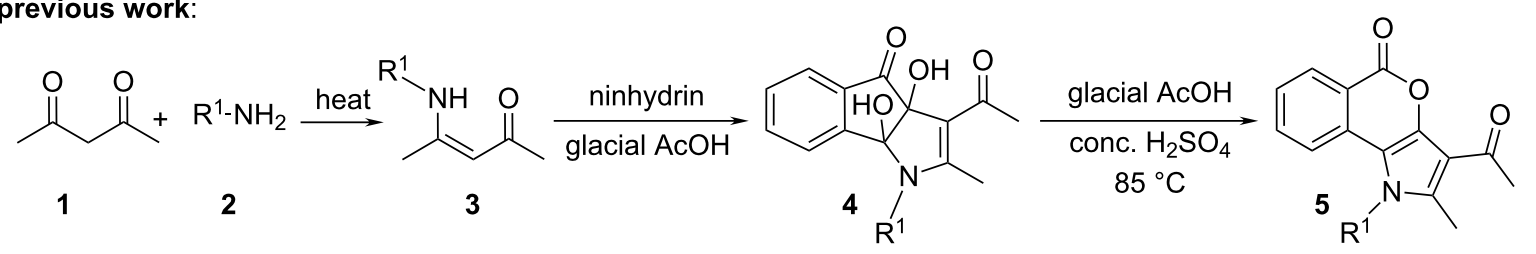

present work :
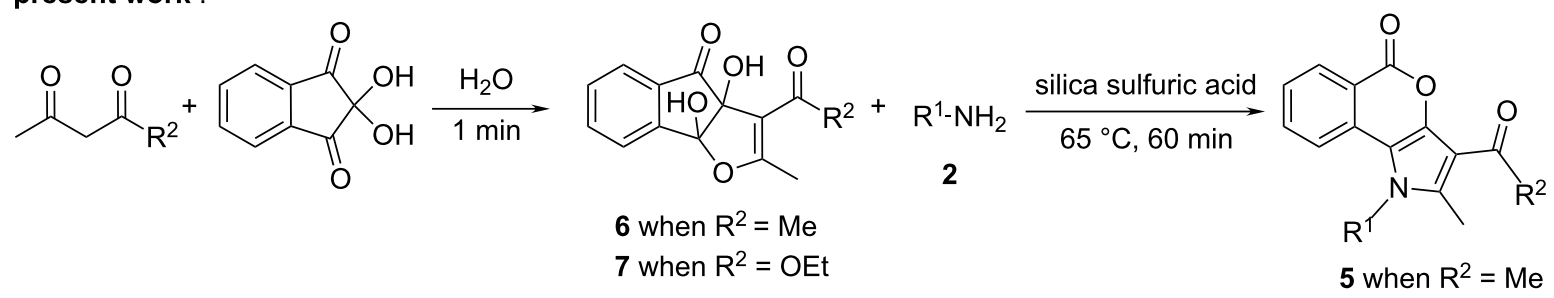

5 when $\mathrm{R}^{2}=\mathrm{Me}$

8 when $\mathrm{R}^{2}=\mathrm{OEt}$ 
between dihydroxyindenofuran ethyl ester 7 [43] and aniline in a molar ration of 1.00:1.50 (Scheme 2). When the reaction was carried out in aqueous solution under reflux the reaction did not proceed at all (Table 1, entry 1). Previous results showed that an activation by a Brønsted acid was necessary to carry out the reaction successfully [38]. Therefore, we screened various Brønsted acid catalysts, e.g., lactic acid, formic acid, citric acid and acetic acid in aqueous solution under reflux. But the yields were very low even after prolonged reaction time (Table 1, entries 2-5). On the basis of the assumption that more acidic conditions might be necessary to furnish the desired products in high yields, we carried out the reaction in acetic acid with adding a catalytic amount of $\mathrm{H}_{2} \mathrm{SO}_{4}$. Intriguingly, the yield of the product increased from less than $10 \%$ to $64 \%$ (Table 1 , entry 6). The structure of the product 8a was confirmed by IR, ${ }^{1} \mathrm{H}$ NMR and ${ }^{13} \mathrm{C}$ NMR spectroscopy and elemental analysis. Surprisingly, when the above-mentioned reaction was carried out with aliphatic amines, only the acetylated amines were obtained instead of the desired products $\mathbf{8}$. These results influenced us to carry out the reaction under greener and milder reaction conditions, but with satisfying yield of the desired product, both for aromatic and aliphatic amines. We restrained the reaction to using $\mathrm{PEG}-\mathrm{OSO}_{3} \mathrm{H}$ as a Brønsted acid-surfactant combined catalyst in aqeous solution under refluxing conditions as well as under solvent-free conditions (Table 1, entries 7 and 8). Although under solvent-free conditions the required temperature was lower and the yields of the products were higher, the yields were still only moderate. This encouraged us<smiles>CCOC(=O)C1=C(C)OC23OC(=O)c4ccccc4C12OC3=O</smiles>

7<smiles>CCOC(=O)c1c(C)n(-c2ccccc2)c2c1oc(=O)c1ccccc12</smiles>

$8 a$

Scheme 2: Reaction scheme for the synthesis of pyrrole-fused isocoumarins.

Table 1: Optimization of reaction conditions for the synthesis of $\mathbf{8 a}$.

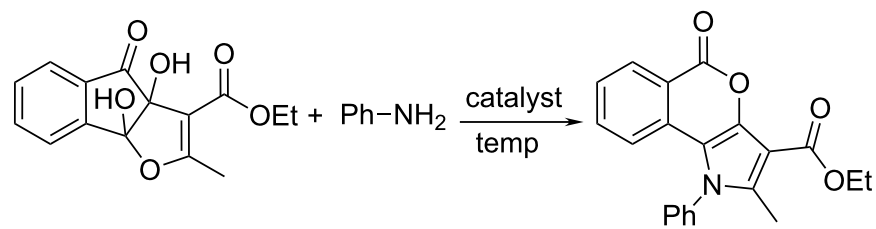

7

$8 \mathbf{a}$

\begin{tabular}{|c|c|c|c|c|c|c|}
\hline entry & catalyst & solvent & catalyst load & temperature $\left({ }^{\circ} \mathrm{C}\right)$ & time $(\mathrm{h})$ & yield $(\%)^{a}$ \\
\hline 1 & - & $\mathrm{H}_{2} \mathrm{O}$ & - & 100 & 24 & - \\
\hline 2 & lactic acid & $\mathrm{H}_{2} \mathrm{O}$ & $20 \mathrm{~mol} \%$ & 100 & 24 & 5 \\
\hline 3 & formic acid & $\mathrm{H}_{2} \mathrm{O}$ & $20 \mathrm{~mol} \%$ & 100 & 24 & 8 \\
\hline 4 & citric acid & $\mathrm{H}_{2} \mathrm{O}$ & $20 \mathrm{~mol} \%$ & 100 & 24 & 5 \\
\hline 5 & acetic acid & $\mathrm{H}_{2} \mathrm{O}$ & $20 \mathrm{~mol} \%$ & 100 & 24 & 6 \\
\hline 6 & $\mathrm{H}_{2} \mathrm{SO}_{4}$ & acetic acid & $20 \mathrm{~mol} \%$ & 85 & 1 & 64 \\
\hline 7 & PEG-OSO $3 \mathrm{H}$ & $\mathrm{H}_{2} \mathrm{O}$ & $500 \mathrm{mg}$ & 100 & 2 & 45 \\
\hline 8 & PEG-OSO ${ }_{3} \mathrm{H}$ & - & $500 \mathrm{mg}$ & 80 & 1.5 & 66 \\
\hline 9 & silica gel & - & $500 \mathrm{mg}$ & 100 & 24 & - \\
\hline 10 & melamine sulphonic acid & - & $500 \mathrm{mg}$ & 100 & 24 & - \\
\hline 11 & silica sulfuric acid & - & $500 \mathrm{mg}$ & 100 & 0.5 & 45 \\
\hline 12 & silica sulfuric acid & - & $500 \mathrm{mg}$ & 85 & 0.5 & 58 \\
\hline 13 & silica sulfuric acid & - & $500 \mathrm{mg}$ & 65 & 1 & 90 \\
\hline 14 & silica sulfuric acid & - & $400 \mathrm{mg}$ & 65 & 1 & 90 \\
\hline 15 & silica sulfuric acid & - & $300 \mathrm{mg}$ & 65 & 1.5 & 83 \\
\hline
\end{tabular}

aOptimization studies were carried out with $1.0 \mathrm{mmol} 7$ and $1.5 \mathrm{mmol}$ of aniline. 
to execute the optimization study in presence of a solid acid catalyst under solvent-free conditions. This is one important facet of green chemistry: the eradication of solvents in chemical processes. Hence, we have carried out the synthesis by dissolving the substrate 7 and aniline in a minimum volume of chloroform, soaked them on the solid surface of solid Brønsted acid catalysts, such as silica gel and melamine sulfonic acid (MSA), dried the mixture under vacuum, and heated the reaction mixture to $100{ }^{\circ} \mathrm{C}$ (Table 1, entries 9 and 10). Unfortunately, the reactions on silica gel and MSA failed to give the desired product $\mathbf{8 a}$. In the search of a suitable solid acid catalyst we employed silica sulfuric acid (SSA) at $100{ }^{\circ} \mathrm{C}$. However, the reaction mixture got charred after $0.5 \mathrm{~h}$ and a considerable amount of impurities along with the desired product 8a was formed (Table 1, entry 11). When lowering the reaction temperature $\left(65-100{ }^{\circ} \mathrm{C}\right)$ and varying the amount (300-500 mg) of solid catalyst (Table 1, entries 12-15), the maximum yield (90\%) of 8 a was obtained at $65{ }^{\circ} \mathrm{C}$ using $400 \mathrm{mg}$ of SSA (Table 1, entry 14).

Having successfully prepared $\mathbf{8 a}$, we decided to explore the scope and generality of this reaction in the synthesis of other analogues. Accordingly, the ninhydrin adducts of acetylacetone/ ethyl acetoacetate (6 and 7) [43] were reacted with a variety of commercially available aliphatic and aromatic primary amines under the optimized conditions (Table 1, entry 14). As becomes evident from Table 2, all the primary amines reacted well with adducts $\mathbf{6}$ and $\mathbf{7}$ affording the desired products $\mathbf{5}$ and $\mathbf{8}$ in good yields. The results show that solvent-free conditions and the SSA catalyst are crucial carrying out the reaction succesfully even with aliphatic amines. The structures of the new products $\mathbf{8 a}-\mathbf{0}$ were determined by using spectroscopic data and elemental analysis. X-ray crystal data analysis of compound $\mathbf{8 c}$ further confirmed the product formation (Figure 1). The formation of products $\mathbf{5 a}-\mathbf{l}$ was confirmed by comparing the reported spectral data and melting points (Table 2) [38].

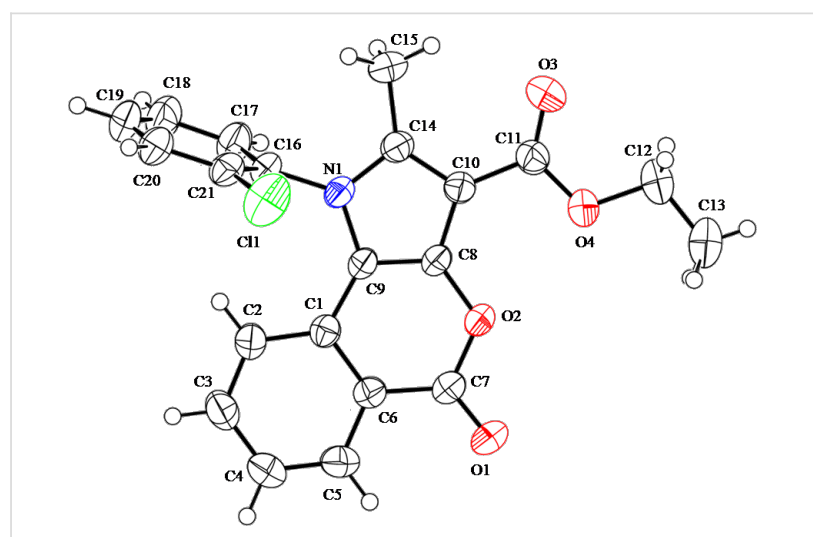

Figure 1: ORTEP diagram of $8 \mathrm{c}$ with atom numbering scheme. Thermal ellipsoids are shown at 50\% probability with CCDC number 949317.

Table 2: Formation of isocoumarins 5 and 8 from adducts 6 and 7 respectively on an SSA surface.

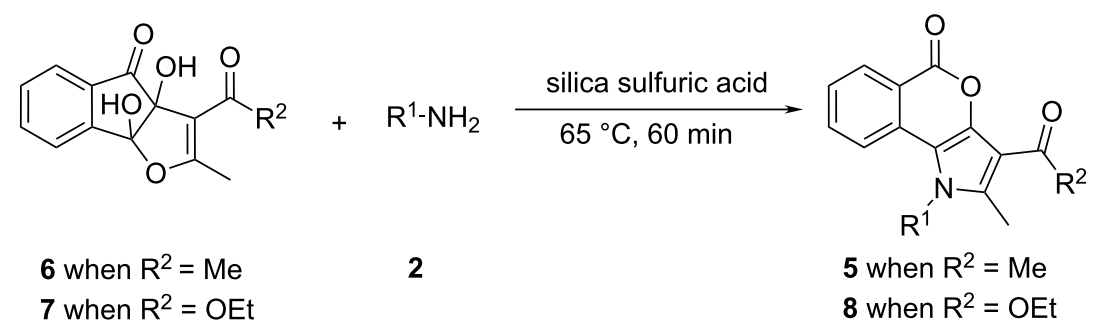

\begin{tabular}{|c|c|c|c|c|c|c|}
\hline entry & $\mathrm{R}^{1}$ & $\mathrm{R}^{2}$ & adduct & product & yield $(\%)^{a}$ & $\mathrm{mp}$ observed/lit. [38] $\left({ }^{\circ} \mathrm{C}\right)$ \\
\hline 1 & & $\mathrm{Me}$ & 6 & $5 a$ & 91 & $248-250 / 248$ \\
\hline 2 & & $\mathrm{Me}$ & 6 & $5 b$ & 82 & $205-207 / 205$ \\
\hline 3 & & Me & 6 & $5 c$ & 88 & $262-264 / 262$ \\
\hline 4 & & $\mathrm{Me}$ & 6 & $5 d$ & 89 & $258-260 / 258$ \\
\hline
\end{tabular}


Table 2: Formation of isocoumarins 5 and 8 from adducts 6 and 7 respectively on an SSA surface. (continued)

6<smiles>COc1ccc(C)cc1</smiles>

$\mathrm{Me}$

$\mathrm{Me}$<smiles>[Y]c1cccc(O)c1</smiles>

8

9<smiles>[Y]c1ccc(Br)cc1</smiles><smiles>[Y]c1ccc([N+](=O)[O-])cc1</smiles>

10<smiles>[Y]c1cccc([N+](=O)[O-])c1</smiles>

11

12

13

14

15

16<smiles>[3H]CCC</smiles><smiles>[Y]Cc1ccccc1</smiles><smiles>[Y]c1ccccc1</smiles><smiles>[Y]c1ccc(F)cc1</smiles><smiles>[Y]c1ccccc1Cl</smiles>

OEt

OEt<smiles>[Y]c1cccc(Cl)c1</smiles>

17<smiles>[Y]c1ccc(Cl)cc1</smiles>

OEt<smiles></smiles>

19<smiles>[Y]c1cccc(OC)c1</smiles>

20<smiles>[Y]c1cccc(O)c1</smiles>

21<smiles>[Y]c1ccc(C)cc1</smiles>

22<smiles>Cc1ccc(C)c(C)c1</smiles>

OEt

OEt

OEt

OEt

OEt
6

$5 e$

$5 f$

$5 g$

5 h

$5 i$

5j

$5 k$

5

$8 a$

$8 b$

$8 c$

8d

8 e

$8 f$

$8 g$

$8 h$

$8 i$

8j
84

80

172-174/172

79

236-238/236

82

86

84

90

88

90

89

79

233-235

7
81

190-192 
Table 2: Formation of isocoumarins 5 and 8 from adducts 6 and 7 respectively on an SSA surface. (continued)

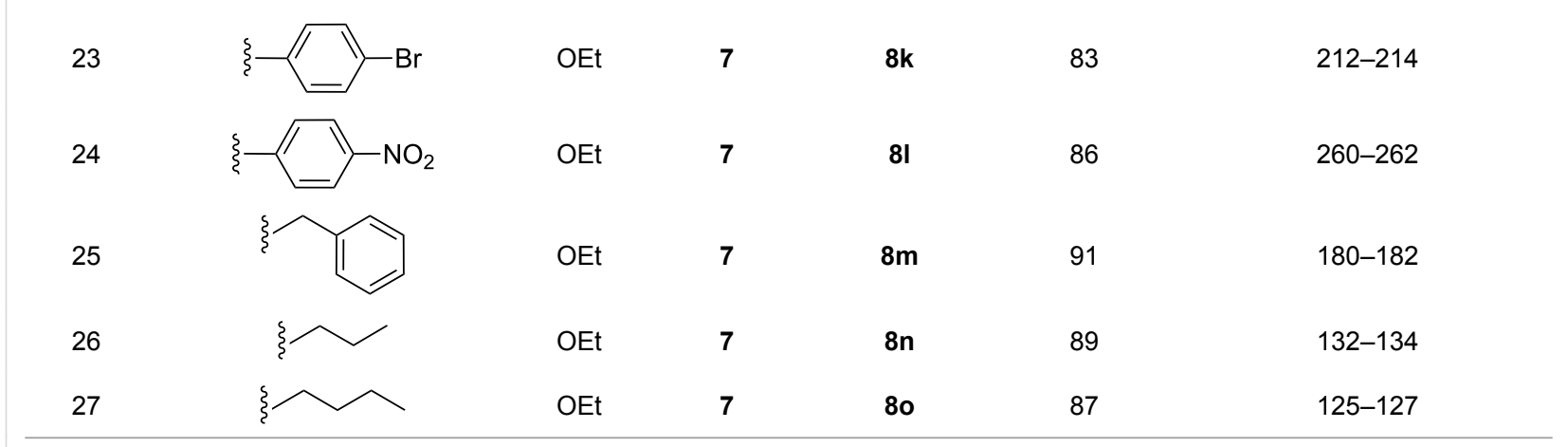

asolated yield.

The comparative studies in terms of overall reaction times and product yields show that although the present method takes more time than the previous method [38], the overall yields of the products are larger in the present method (Table 3 ). More importantly the present method enables us to access a new series of pyrrole-fused isocoumarins with ester functionality (Table 3, compounds 8a-o), which were not possible to synthesize with the previous method. Apart from that the present method is more advantageous in terms of product formation and greener characteristics than the previous one in many respects such as (a) a less laborious and more step-economical reaction for the library synthesis of pyrrole-fused isocoumarin deriva- tives, since the starting materials dihydroxy indenofurans 6 and 7 need only one step for preparation, (b) the employment of milder acidic conditions, (c) a lower reaction temperature $\left(65^{\circ} \mathrm{C}\right),(\mathrm{d})$ solvent-free conditions, and (e) more cost-effective because of the reusability of the solid-supported SSA. Moreover the starting materials 6 and 7 can also be prepared through a green methodology [43].

Based on the results of Table 2 and the fact that SSA plays the role of transferring protons from its solid surface, a probable mechanism for the formation of isocoumarins $\mathbf{5}$ or $\mathbf{8}$ is explicated in Scheme 3. The protonation and activation of the

Table 3: Comparison between the present and the previous method for the synthesis of pyrrole-fused isocoumarins from ninhydrin.

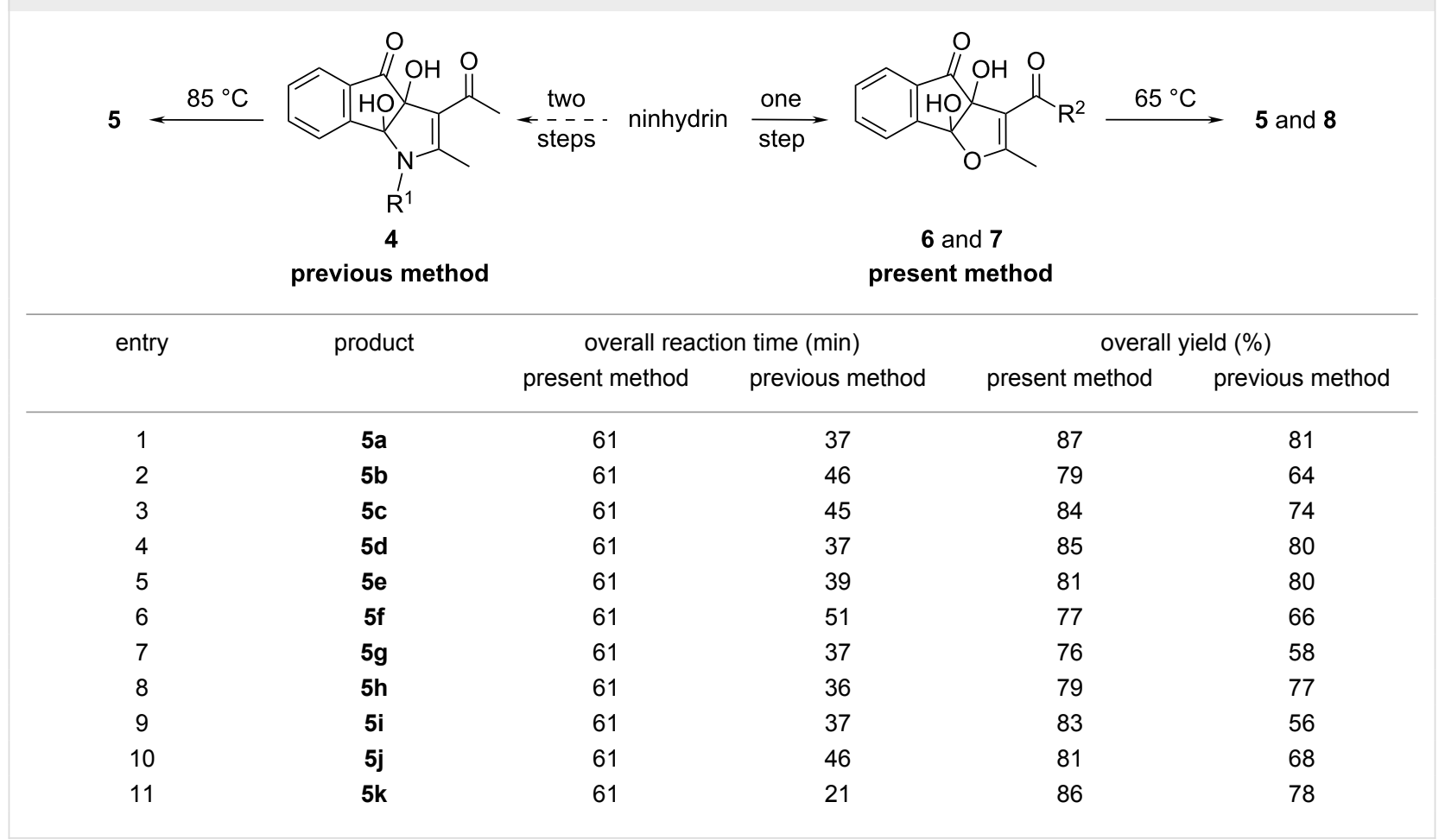


Table 3: Comparison between the present and the previous method for the synthesis of pyrrole-fused isocoumarins from ninhydrin. (continued)

$\begin{array}{llllll}12 & \mathbf{5 1} & 61 & 25 & 84 & 84 \\ 13 & \mathbf{8 a} & 61 & - & 84 & - \\ 14 & \mathbf{8 b} & 61 & - & 83 & - \\ 15 & \mathbf{8 c} & 61 & - & 73 & - \\ 16 & \mathbf{8 d} & 61 & - & 79 & - \\ 17 & \mathbf{8 e} & 61 & - & 81 & - \\ 18 & \mathbf{8 f} & 61 & - & 74 & - \\ 19 & \mathbf{8 g} & 61 & - & 77 & - \\ 20 & \mathbf{8 h} & 61 & - & 75 & - \\ 21 & \mathbf{8} & 61 & - & 80 & - \\ 22 & \mathbf{8 j} & 61 & - & 75 & - \\ 23 & \mathbf{8 k} & 61 & - & 77 & - \\ 24 & \mathbf{8 1} & 61 & - & 80 & - \\ 25 & \mathbf{8 m} & 61 & - & 85 & - \\ 26 & \mathbf{8 n} & 61 & - & 83 & - \\ 27 & \mathbf{8 0} & 61 & - & 81 & -\end{array}$

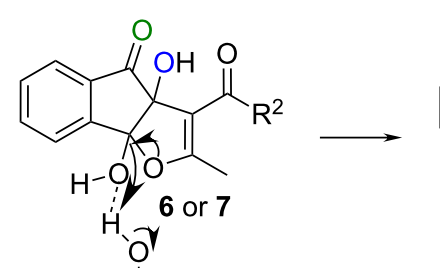

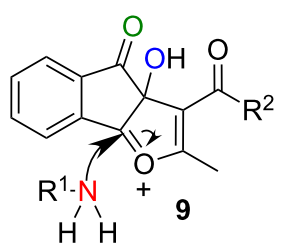

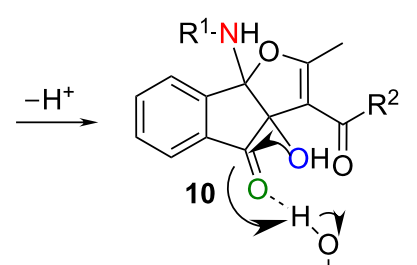

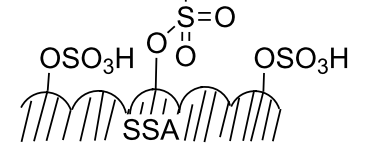

$\mathrm{H} \mathrm{H}$

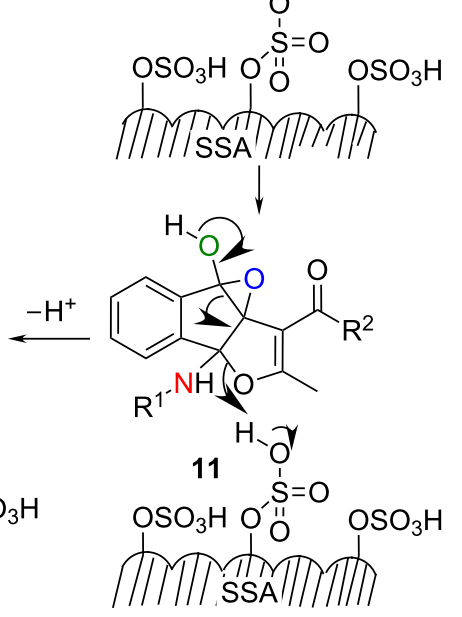

$\mathrm{OSO}_{3} \mathrm{H} \mathrm{OSO} \mathrm{H}_{3} \mathrm{O}^{\prime \prime O}$

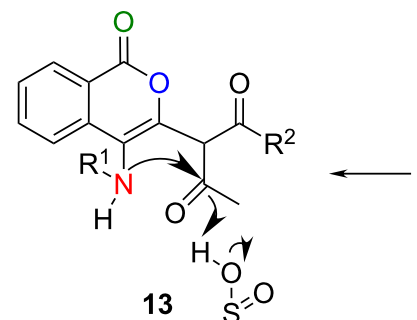

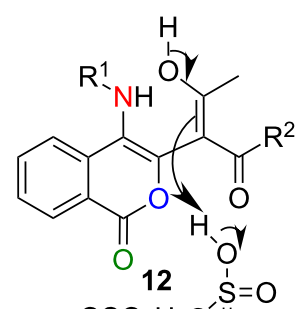

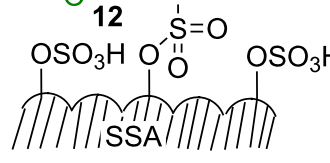
M Missa IITIII

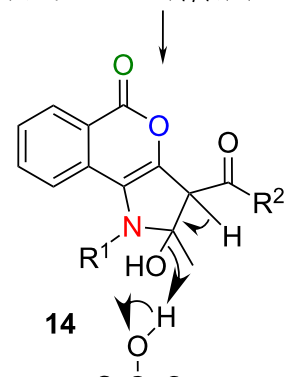<smiles>[R]C(=O)c1c(C)n([R19])c2c1oc(=O)c1ccccc12</smiles>

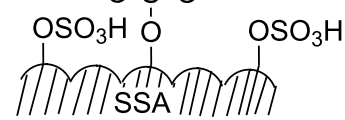


hydroxy group of dihydroxy indenofuran ( 6 or 7) by the sulfonic group of SSA generates dehydrated cationic intermediate 9. This reactive intermediate 9 provokes a nucleophilic attack of primary amines to form bicyclo[3.3.0]octanamino compound $\mathbf{1 0}$. Then the $\alpha$-hydroxy group of $\mathbf{1 0}$ attacks the adjacent carbonyl carbon to generate epoxy intermediate 11. This unstable epoxy intermediate $\mathbf{1 1}$ produces a six-membered lactone intermediate $\mathbf{1 2}$ through the breaking of a $\mathrm{C}-\mathrm{C}$ bond. Subsequently, intermediate $\mathbf{1 2}$ tautomerizes to $\mathbf{1 3}$ under formation of the isocoumarin skeleton. The dihydropyrrole-fused isocoumarin intermediate $\mathbf{1 4}$ is formed through the intramolecular nucleophilic attack of the secondary amine group to the carbonyl carbon of 13. Finally, intermediate $\mathbf{1 4}$ loses water to furnish pyrrole-fused isocoumarins $\mathbf{5}$ or $\mathbf{8}$. It is worth mentioning that in the previous method instead of the formation of epoxy intermediate like $\mathbf{1 1}$ a transannular rearrangement was proposed for the product formation [38], because the formation of epoxy intermediate is less probable in the presence of a strong acid and a nucleophilic solvent as well as at higher temperatures.

Furthermore, a test with respect to recovery and reusability of SSA for the formation of $\mathbf{8 a}$ was carried out. After heating the mixture of aniline and adduct 7 on the solid surface of SSA for $1 \mathrm{~h}$, the product $\mathbf{8 a}$ was isolated easily with ethylacetate by sonication of the reaction mixture. The recovered solidsupported SSA was reused five times, and the yield of the product 8a varied from $90-83 \%$, which indicates a substantial retention of catalytic activity and efficiency of SSA even after repeated application (Figure 2).

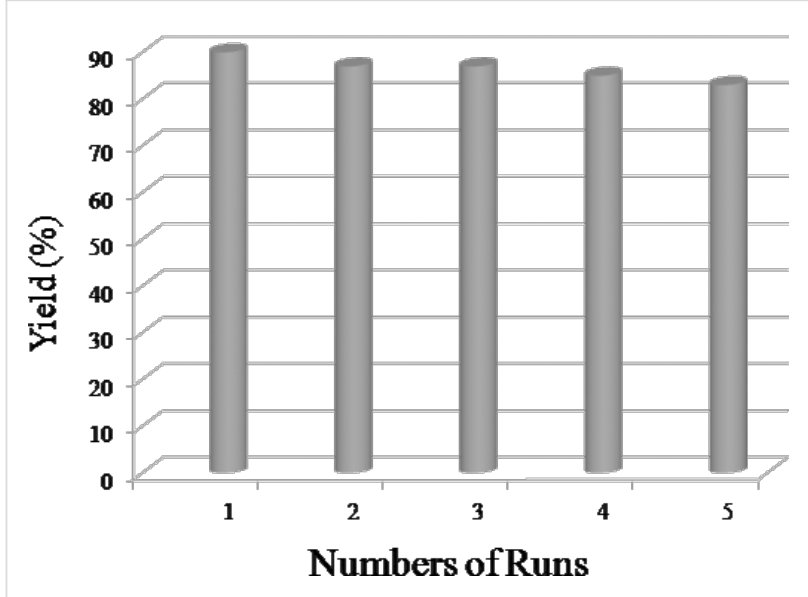

Figure 2: Reusability of SSA for the synthesis of pyrrole-fused isocoumarins.

\section{Conclusion}

In conclusion, a facile and convenient methodology has been developed for the synthesis of a diverse range of $N$-substituted pyrrole-fused isocoumarins in presence of the solid-supported Brønsted acid catalyst silica sulfuric acid (SSA). The methodology has a series of intrinsic advantages such as easy preparation of the solid supported SSA from chlorosulfonic acid and silica gel, less energy and manpower usage, easy product isolation/purification and operational simplicity, which lead to the synthetic route "benign by design". This is the first report, in which a rearrangement reaction has been carried out on the solid surface of SSA. Overall this greener and environmentally friendly method may attract the fellow chemists in chemical and pharmaceutical industries for the synthesis of biologically important pyrrole-fused isocoumarins.

\section{Experimental}

General information: Starting materials and solvents were purchased from commercial suppliers and used without further purification. Melting points were determined in open capillary tubes and were uncorrected. IR spectra were recorded on a Perkin-Elmer 782 spectrophotometer. ${ }^{1} \mathrm{H}$ (300 MHz) and ${ }^{13} \mathrm{C}$ NMR (75 MHz) spectra were recorded on a Bruker $300 \mathrm{MHz}$ instrument in $\mathrm{CDCl}_{3}$ and $d_{6}$-DMSO. Elemental analyses $(\mathrm{C}, \mathrm{H}$ and $\mathrm{N})$ were performed by using a Perkin-Elmer $240 \mathrm{C}$ elemental analyzer. The X-ray diffraction data for crystallized compounds were collected with Mo K $\alpha$ radiation at $296 \mathrm{~K}$ using the Bruker APEX-II CCD System. The crystals were positioned at $50 \mathrm{~mm}$ from the CCD. Frames were measured with a counting time of $5 \mathrm{~s}$. Data analyses were carried out with the Bruker APEX2 and Bruker SAINT program. The structures were solved using direct methods with the SHELXS97 program.

\section{General experimental procedure for synthesis of pyrrole-} fused isocoumarins 5 and 8: A mixture of primary amines 2 $(1.5 \mathrm{mmol})$ and dihydroxy indenofurans 6 or $7(1.0 \mathrm{mmol})$ in chloroform $(5 \mathrm{~mL})$ was soaked in SSA (400 mg) by stirring for $10 \mathrm{~min}$ and then the solvent was removed under reduced pressure to get a solid mass. The solid mass was heated at $65^{\circ} \mathrm{C}$ for $1 \mathrm{~h}$ under continuous stirring, until the complete disappearance of dihydroxyindenofuran was observed (as monitored by TLC). After cooling the solid mass to room temperature, ethylacetate $(15 \mathrm{~mL})$ was added to it, shaken thoroughly, ultra-sonicated and filtered to remove the SSA catalyst. The separated organic phase was evaporated under reduced pressure to get the crude product $\mathbf{5}$ or $\mathbf{8}$ which was purified by column chromatography (hexane/EtOAc).

Reusability of the SSA: After completion of the reaction, the product was isolated by ultra-sonication with ethylacetate and decanted. Then the separated solid catalyst SSA was dried under vacuum and reused directly for a new reaction set. The yield of the product 8 a varied from $90-83 \%$ after five consecu- 
tive cycles without any serious loss of efficiency of the solid supported SSA (Figure 2).

\section{Supporting Information}

Supporting Information features detailed analytical data of the prepared compounds and a collection of NMR spectra.

\section{Supporting Information File 1}

Detailed analytical data.

[http://www.beilstein-journals.org/bjoc/content/ supplementary/1860-5397-9-269-S1.pdf]

\section{Acknowledgements}

S.P. and K.D. thank CSIR and UGC, New Delhi, India, for offering a Senior Research Fellowship (SRF) and a Junior Research Fellowship (JRF) respectively. The financial assistance of CSIR, New Delhi is gratefully acknowledged [Major Research Project, No. 02(0007)/11/EMR-II]. Crystallography was performed at the DST-FIST, India-funded Single Crystal Diffractometer Facility at the Department of Chemistry, University of Calcutta.

\section{References}

1. Zhang, W.; Krohn, K.; Draeger, S.; Schulz, B. J. Nat. Prod. 2008, 71, 1078-1081. doi:10.1021/np800095g

2. Lu, X.; Li, D.; Dalley, N. K.; Wood, S. G.; Owen, N. L. Nat. Prod. Res. 2007, 21, 677-685. doi:10.1080/14786410500463395

3. Pal, S.; Chatare, V.; Pal, M. Curr. Org. Chem. 2011, 15, 782-800. doi:10.2174/138527211794518970

4. De Abreu, H. A.; dos S. Lago, I. A.; Souza, G. P.; Piló-Veloso, D.; Duarte, H. A.; de C. Alcântara, A. F. Org. Biomol. Chem. 2008, 6, 2713-2718. doi:10.1039/B804385J

5. Nakhi, A.; Adepu, R.; Rambabu, D.; Kishore, R.; Vanaja, G. R.; Kalle, A. M.; Pal, M. Bioorg. Med. Chem. Lett. 2012, 22, 4418-4427. doi:10.1016/j.bmcl.2012.04.109

6. Yadav, P.; Purohit, N. V. Indian J. Pharm. Sci. 2011, 73, 171-178. doi:10.4103/0250-474X.91586

7. Uchiyama, M.; Ozawa, H.; Takuma, K.; Matsumoto, Y.; Yonehara, M.; Hiroya, K.; Sakamoto, T. Org. Lett. 2006, 8, 5517-5520. doi:10.1021/ol062190+

8. Özcan, S.; Şahin, E.; Balci, M. Tetrahedron Lett. 2007, 48, 2151-2154. doi:10.1016/j.tetlet.2007.01.098

9. Soleimani, E.; Zainali, M. J. Org. Chem. 2011, 76, 10306-10311. doi:10.1021/jo201908f

10. Kavala, V.; Wang, C.-C.; Barange, D. K.; Kuo, C.-W.; Lei, P.-M.; Yao, C.-F. J. Org. Chem. 2012, 77, 5022-5029. doi:10.1021/jo300501j

11. Chary, R. G.; Reddy, G. R.; Ganesh, Y. S. S.; Prasad, K. V.; Chandra, S. K. P.; Mukherjee, S.; Pal, M. RSC Adv. 2013, 3, 9641-9644. doi:10.1039/C3RA40969D

12. Suzuki, T.; Yamada, T.; Watanabe, K.; Katoh, T. Bioorg. Med. Chem. Lett. 2005, 15, 2583-2585. doi:10.1016/j.bmcl.2005.03.043
13. Deponti, M.; Kozhushkov, S. I.; Yufit, D. S.; Ackermann, L. Org. Biomol. Chem. 2013, 11, 142-148. doi:10.1039/C2OB26250A

14. Li, Z.; Hong, J.; Weng, L.; Zhou, X. Tetrahedron 2012, 68, 1552-1559. doi:10.1016/j.tet.2011.12.003

15. da Penha, E. T. D.; Forni, J. A.; Biajoli, A. F. P.; Correia, C. R. D. Tetrahedron Lett. 2011, 52, 6342-6345. doi:10.1016/j.tetlet.2011.09.014

16. Hellal, M.; Bourguignon, J.-J.; Bihel, F. J.-J. Tetrahedron Lett. 2008, 49, 62-65. doi:10.1016/j.tetlet.2007.11.020

17. Chen, P.-Y.; Huang, K.-S.; Tsai, C.-C.; Wang, T.-P.; Wang, E.-C. Org. Lett. 2012, 14, 4930-4933. doi:10.1021/ol302256y

18. Munro, T. A.; Duncanl, K. K.; Staples, R. J.; Xu, W.; Liu-Chen, L.-Y.; Béguin, C.; Carlezon, W. A., Jr.; Cohen, B. M. Beilstein J. Org. Chem. 2007, 3, No. 1. doi:10.1186/1860-5397-3-1

19. Reddy, G. R.; Reddy, T. R.; Joseph, S. C.; Reddya, K. S.; Pal, M. RSC Adv. 2012, 2, 3387-3395. doi:10.1039/c2ra00982j

20. Reddy, G. R.; Reddy, T. R.; Joseph, S. C.; Reddy, K. S.; Reddy, L. S.; Kumar, P. M.; Krishna, G. R.; Reddy, C. M.; Rambabu, D.; Kapavarapu, R.; Lakshmi, C.; Meda, T.; Priya, K. K.; Parsad, K. V. L.; Pal, M. Chem. Commun. 2011, 47, 7779-7781. doi:10.1039/c1cc12321a

21. Maiti, S.; Biswas, S.; Jana, U. J. Org. Chem. 2010, 75, 1674-1683. doi:10.1021/jo902661y

22. Varma, R. S. Green Chem. 1999, 1, 43-55. doi:10.1039/A808223E

23. Sathishkumar, M.; Nagarajan, S.; Shanmugavelan, P.; Dinesh, M.; Ponnuswamy, A. Beilstein J. Org. Chem. 2013, 9, 689-697. doi:10.3762/bjoc.9.78

24. Bougrin, K.; Soufiaoui, M. Tetrahedron Lett. 1995, 36, 3683-3686. doi:10.1016/0040-4039(95)00611-F

25. Azizian, J.; Karimi, A. R.; Kazemizadeh, Z.; Mohammadi, A. A.; Mohammadizadeh, M. R. Synthesis 2005, 1095-1098. doi:10.1055/s-2005-861870

26. Zolfigol, M. A. Tetrahedron 2001, 57, 9509-9511. doi:10.1016/S0040-4020(01)00960-7

27. Chen, W.-Y.; Lu, J. Synlett 2005, 2293-2296. doi:10.1055/s-2005-872654

28. Khodaei, M. M.; Khosropour, A. R.; Fattahpour, P. Tetrahedron Lett. 2005, 46, 2105-2108. doi:10.1016/j.tetlet.2005.01.149

29. Saheli, P.; Dabiri, M.; Zolfigol, M. A.; Baghbanzadeh, M. Synlett 2005, 1155-1157. doi:10.1055/s-2005-865200

30. Saheli, P.; Dabiri, M.; Zolfigol, M. A.; Baghbanzadeh, M. Tetrahedron Lett. 2005, 46, 7051-7053. doi:10.1016/j.tetlet.2005.08.043

31. Shirini, F.; Zolfigol, M. A.; Mohammadi, K. Bull. Korean Chem. Soc. 2004, 25, 325-327. doi:10.5012/bkcs.2004.25.2.325

32. Mirjalili, B. F.; Zolfigol, M. A.; Bamoniri, A. Molecules 2002, 7, 751-755 doi:10.3390/71000751

33. Hajipour, A. R.; Zarei, A.; Khazdooz, L.; Pourmousavi, S. A.; Ruoho, A. E. Bull. Korean Chem. Soc. 2005, 26, 808-810. doi:10.5012/bkcs.2005.26.5.808

34. Chakraborti, A. K.; Singh, B.; Chankeshwara, S. V.; Patel, A. R. J. Org. Chem. 2009, 74, 5967-5974. doi:10.1021/jo900614s

35. Maleki, B.; Keshvari-Shirvan, H.; Taimazi, F.; Akbarzadeh, E. Int. J. Org. Chem. 2012, 2, 93-99. doi:10.4236/ijoc.2012.21015

36. Das, S.; Fröhlich, R.; Pramanik, A. Org. Lett. 2006, 8, 4263-4266. doi:10.1021/ol061520n

37. Das, S.; Koley, P.; Pramanik, A. Tetrahedron Lett. 2011, 52, 3243-3246. doi:10.1016/j.tetlet.2011.04.076

38. Pathak, S.; Kundu, A.; Pramanik, A. Tetrahedron Lett. 2011, 52, 5180-5183. doi:10.1016/j.tetlet.2011.07.133 
39. Das, S.; Fröhlich, R.; Pramanik, A. Synlett 2006, 207-210. doi:10.1055/s-2006-926226

40. Das, S.; Pramanik, A.; Fröhlich, R.; Patra, A. Tetrahedron 2004, 60, 10197-10205. doi:10.1016/j.tet.2004.09.004

41. Pathak, S.; Debnath, K.; Hossain, S. T.; Mukherjee, S. K.; Pramanik, A. Tetrahedron Lett. 2013, 54, 3137-3143. doi:10.1016/j.tetlet.2013.04.015

42. Pathak, S.; Pramanik, A. Eur. J. Org. Chem. 2013, 4410-4417. doi:10.1002/ejoc.201300096

43. Chakrabarty, M.; Mukherji, A.; Arima, S.; Harigaya, Y.; Pilet, G. Monatsh. Chem. 2009, 140, 189-197. doi:10.1007/s00706-008-0066-6

\section{License and Terms}

This is an Open Access article under the terms of the Creative Commons Attribution License

(http://creativecommons.org/licenses/by/2.0), which permits unrestricted use, distribution, and reproduction in any medium, provided the original work is properly cited.

The license is subject to the Beilstein Journal of Organic Chemistry terms and conditions:

(http://www.beilstein-journals.org/bjoc)

The definitive version of this article is the electronic one which can be found at: doi:10.3762/bjoc. 9.269 